\title{
DISCUTINDO OS DESAFIOS NO ESPAÇO URBANO: UM ESTUDO NA CIDADE DE MOSSORÓ/RN
}

\section{Ludimilla Carvalho Serafim de Oliveira ${ }^{1}$}

Resumo: A cidade de Mossoró está situada no semi-árido do nordeste brasileiro e tem como uma de suas principais características a atividade econômica baseada na extração de petróleo, o que trouxe para o local um leque de crescimento calcado na cadeia produtiva do mesmo e na terceirização de alguns serviços através das dinâmicas produzidas por meio desse processo produtivo. Com isso, o problema pesquisado parte do princípio que visa refletir os efeitos positivos e negativos ou des(construtores) da cultura e da tradição a partir da concretização das novas centralidades, nessa cidade , a priori, tendo em vista um sensível quadro de mudanças na paisagem, nos estilos de vida e nas dinâmicas intra-urbanas dos espaços produzidos pela valorização econômica em alguns locais.A metodologia utilizada baseia-se numa pesquisa de campo, priorizando sobretudo um eixo de crescimento da cidade com a finalidade de apresentar tais mudanças. Os resultados mostram que a expansão urbana de Mossoró foi deflagrada por um conjunto de circunstâncias e dentre elas a questão econômica merece seu valor. Pois, a infra-estrutura urbana foi sendo construída e melhorada à medida que, os espaços foram sendo demandados e utilizados frente às transformações e inovações do processo de crescimento econômico e social da cidade.

Palavras-chaves: Espaço urbano. Novas centralidades. Metamorfoses do espaço.

\section{Introdução}

\footnotetext{
${ }^{1}$ Especialista em Direito Ambiental, Mestre em Desenvolvimento e Meio Ambiente, Doutoranda em Arquitetura e Urbanismo pelo PPGAU/UFRN, Professora do Departamento de Agrotecnologia e Ciências Sociais da UFERSA (Universidade Federal Rural do Semi-árido). E-mail: ludimillaoliveira@globo.com.
} 
O crescimento urbano, acelerado e rápido, em países emergentes tem apresentado um conjunto de tendências que desafia a governança das cidades em pleno século XXI, e frente a este referencial de transformações os investimentos tem acontecido em diferentes escalas ou setores, isto é: por particulares (sociedade civil); pelos investidores do ramo imobiliário e por parte do Estado. Contudo, esta hierarquia de investidores nos remete a reflexão: o que tem motivado as atuais mudanças no espaço urbano?

Assim, a cidade de Mossoró/RN, como campo empírico para esta exposição, permite numa reflexão panorâmica sobre esta localidade, mostrar que: sua expansão urbana está em vias de acontecimento, observando-se diferentes categorias investindo no espaço urbano tendo como conseqüência uma ampliação das atividades econômicas. Por isso, o estudo propõe-se a avaliar o processo de concretização dessas novas centralidades, a priori, tendo em vista um sensível quadro de mudanças na paisagem, nos estilos de vida e nas dinâmicas intra-urbanas dos espaços públicos a partir da descentralização do uso e na ocupação solo urbano.

Villaça (1998) destaca que a classe de alta renda de uma cidade, geralmente se concentra em uma mesma direção. Assim, eles se auto-segregam e controlam o seu espaço (há uma bipartição do espaço urbano, criando duas cidades distintas). Qual tal classe se concentra em determinado local acaba promovendo outras áreas para a classe de baixa renda. Com isso, tais áreas se tornam valorizadas e o valor do terreno sofre acréscimos consideráveis.

Atenta a questão, o trabalho tem como objetivo estudar as metamorfoses dos espaços construídos nas localidades centrais e os sentidos que norteiam o processo de valorização no espaço intra-urbano e sua dinâmica, por meio da formação de centralidades. A partir dessa premissa é defendido como tese a seguinte assertativa: As dinâmicas construídas nos espaços urbanos transformados servem para a concretização de áreas centrais. Os agentes desse processo promovem novas centralidades a partir do uso e da ocupação desses espaços.

De acordo com Silveira e Ribeiro (2008), à produção das chamadas novas centralidades, corresponde a um termo utilizado para designar espaços que favorecem a uma dinâmica que os tornam destinações coletivas polarizadoras. A teoria das 
localidades centrais foi formulada pelo geógrafo alemão Walter Christaller em 1933. De um modo geral, uma parte considerada central de um espaço está associada à acessibilidade, enquanto ponto principal para a qualificação de sua localização na cidade.

É relevante destacar, que nesse ínterim a influência das políticas neoliberais merecem seu valor, as quais, segundo Teixeira e Oliveira (org) (1998, p. 121), correspondem as transformações produtivas intrínsecas a um contexto político e ideológico de uma nova fase do capitalismo, em que o Estado organiza-se, em prol da minimização de seus custos com políticas sociais e adequa-se às novas condições de acumulação do capital, tendo como principal suporte ideológico o livre mercado. Tal perspectiva, trouxe consigo inúmeras mudanças nas formas de produção e de consumo, além de ter atrelado a esta dinâmica um processo denominado globalização, que pode ser compreendido nos aspectos:econômicos, políticos, culturais, sociais e ambientais influenciando sobretudo nas atuais transformações do espaço urbano. .

Tal processo, permite perceber o grau de mudança que este produz. Pois, as dinâmicas econômicas introduzidas na sociedade, nem sempre vem acompanhadas com o desenvolvimento e as cidades neste percurso passam por muitas intempéries sociais. Isto é, o agravamento da questão social, do caos e da disrupção política.

A diferença, portanto, reside na concentração, em virtude da qual alguns milhares de ricos e alguns milhões de indivíduos da classe média foram levados a um estreito contato com milhões de pobres e indigentes. Nesse sentido, a industrialização e a urbanização, com soem dizer os marxistas, criaram uma nova série de relações sociais e uma nova série de percepções sociais (HALL, 2005, p. 50).

A crescente urbanização concentra no espaço construído, uma conjunção de forças produtivas aliadas às forças do trabalho, a qual transforma as propulsões dispersas e sistemas descentralizados de direitos frente ao poder político e econômico. Pois, o espaço ao mesmo tempo em que concentra, através da forma as transformações da estrutura social, também articula - se com as práticas dos agentes sociais na cidade como um elemento ativo. Desse modo, a articulação entre a 
produção, reprodução e apropriação do espaço intra-urbano tornam evidentes as implicações físico-territoriais e sociais capazes de formar novas centralidades.

Portanto, as idéias que permeiam esta pesquisa pretendem contribuir com a ciência para consolidar este importante conceito, baseando-se, contudo, na metamorfose do espaço e com ela a introdução de dinâmicas, promotoras da construção de centralidades. Qual, na atualidade está à frente dos discursos das transformações urbanas atrelada principalmente a processos gentrificadores. Principalmente, pelo fato de sua gênese está ligada aos países desenvolvidos e no Brasil, ainda aparecer de maneira incipiente, isto é, isolada. Daí a relevância e a fundamentação se tornarem necessárias para aprimorar os estudos teóricos e empíricos no que diz respeito às questões urbanas em países da América Latina, como o Brasil.

\section{Mossoró: Uma história, um lugar...}

A cidade de Mossoró está situada no semi-árido do nordeste brasileiro e tem como uma de suas principais características a atividade econômica baseada na extração de petróleo, o que trouxe para o local um leque de crescimento calcado na cadeia produtiva do mesmo e na terceirização de alguns serviços através das dinâmicas produzidas por meio desse processo produtivo. Contudo, ao longo dos anos este local tem passado por vários ciclos econômicos e dentre eles está à atividade da agricultura; a exploração mineral do calcário e, sobretudo o petróleo, que vem sendo destaque principalmente para o crescimento urbano. Posto que, a cidade tem buscado se adequar aos novos parâmetros de desenvolvimento com, a especulação imobiliária e acima de tudo tendo sido responsável pelo atual crescimento vertical e horizontal da cidade.

De acordo com Pinheiro (2006, p.60) "A cidade de Mossoró, como cidade nordestina de médio porte, assumiu a condição urbana desde meados do século XIX. Desde então, se sucederam diversas especializações econômicas que garantiram a 
sua condição de centro regional para onde convergem diversos contingentes populacionais das áreas circunvizinhas".

Então, a partir da primeira metade da década de 1980, a escala da cidade de Mossoró reproduz a segregação social e espacial decorrente da nova estrutura econômica. As profundas transformações advindas de sua reestruturação produtiva durante a década de 1970, quando a cidade deixa de ser um centro repassador de matérias-primas para ser um centro prestador de serviços, provocaram uma verdadeira reestruturação espacial em seu solo urbano. Neste contexto, a questão do espaço urbano torna-se polêmica e contraditória, pelo fato de atingir as diversas classes sociais de diferentes maneiras.

Ao final da década de 70 o petróleo entra na agenda econômica da cidade. É a partir da instalação da Petrobrás em terras mossoroenses que a hotelaria primeiramente, e posteriormente, o turismo começa a dar sinais da sua presença no espaço urbano. É oportuno ressaltar que na época da instalação da empresa em Mossoró a cidade não oferecia nenhum meio de hospedagem para atender uma grande empresa, nem tampouco para receber um contingente expressivo de funcionários. De inicio o problema de hospedagem foi resolvido com a locação de vários imóveis em diferentes pontos da cidade para acolher esses funcionários em trabalho. A chegada da Petrobrás trouxe dinamismo para os mais diferentes setores (PLANO DIRETOR, 2006, p. 95).

Assim, na primeira metade da década de 1970, a difícil situação gerada pelo desemprego em massa e pela incapacidade dos capitais locais para absorver essa mão-de-obra, incide sobre a débil estrutura urbana de Mossoró. A cidade torna-se uma área de tensões sociais e começa o processo de "inchamento" do seu espaço, com a formação de favelas pelo exército de desempregados das agroindústrias e das salinas, como também pela população rural que migrou assolada pelas secas. Foi nesse contexto que as autoridades governamentais acionaram políticas públicas visando controlar os conflitos.

A instalação do escritório da PETROBRAS, em 1975, para gerenciar o petróleo descoberto na sua área de influência, cria condições para a cidade se transformar num centro prestador de serviços. Com a PETROBRAS e as suas subsidiárias demandando 
por moradias, transportes, lazer, serviços especializados, e a diversificação do comércio local, a atividade terciária foi incorporada à economia da cidade.

É nesse contexto que a cidade concebe seu primeiro Plano Diretor, através da Lei 01 , de 09 de Junho de 1975, numa tentativa de zonear o uso do uso e ordenar o crescimento da cidade considerando o afluxo de novos contingentes populacionais, o desenvolvimento do sistema de transportes, e a demarcação econômica da região. 0 Plano Diretor foi elaborado pela empresa Planos Técnicos do Brasil Ltda., contou com a supervisão da Prefeitura Municipal e com a colaboração técnica da SUDENE e do SERFHAU. No zoneamento, são definidos as zonas e os usos predominantes para residências, comércios, indústrias e serviços. A Zona Urbana do Município de Mossoró, definida pela Lei 07, de 24 de Dezembro de 1973, foi dividida em dez zonas.Ressaltase nessa perspectiva que:

Nas décadas de 1970 e 1980, o Plano Diretor foi em geral acionado na "lógica da falta": era um rol dos investimentos em infra-estrutura ou equipamentos que faltavam para que determinada cidade atingisse um patamar adequado ou desejável de urbanização. Além disso, tratava-se de instrumento construído entre técnicos, pouco ou nada discutido pelos atores que usavam e produziam as cidades. A somatória de propostas irrealizáveis com o deslocamento em relação à agenda política e social das cidades e o desconhecimento generalizado do conteúdo dos planos diretores (até mesmo entre técnicos das próprias prefeituras que encomendavam os planos) resultaram no engavetamento da maior parte dos planos diretores das décadas de 1970 e 1980, e lançaram o instrumento no descrédito (CYMBALISTA, 2006.p. 34).

Com isso, fazendo parte de uma política de planejamento vigente em todo o Brasil desde a década de 1960, a principal preocupação do Plano Diretor em Mossoró era a instalação de uma Zona Industrial, numa área bem maior do que as outras, tendo como objetivo dinamizar a atividade industrial, criando condições suficientes, tais como energia elétrica, acesso, sistema de água e esgotos. Segundo o Plano, a facilidade de recursos naturais ligados às atividades extrativas e minerais, propicia a diversificação industrial, e somente o crescimento orientado disciplinaria a expansão da cidade, a realização das atividades econômicas urbanas (comércio, indústria e serviços), e a 
implantação das políticas de infra-estrutura, saneamento e tráfego, através de programas de curto, médio e longo prazo.

Rocha (2005), afirma que o número de pessoas envolvidas com a mobilidade da força de trabalho pertencente a Indústria Petrolífera em Mossoró é significativa, enquanto condição e produto do processo de acumulação do capital, criados por essa atividade. Contudo, apresenta-se intimamente relacionado com essas construções e com a produção dessas áreas urbanas; confirmando as inter-relações existentes entre a mobilidade dessa força de trabalho e a produção do espaço urbano, quer seja nas áreas centrais ou valorizadas da cidade, quer também da periferia.

Assim, as desigualdades sociais se tornam mais evidentes, uma vez que a intervenção Estatal beneficia maciçamente aquelas classes sociais inseridas no processo produtivo, especialmente as de maior renda; ao mesmo tempo em que expulsa o morador de baixa renda para os conjuntos habitacionais. Dessa forma, as classes sociais se apropriam de maneira diferente dos bens de consumo urbano, tais como transporte, água, luz, saneamento, ensino, saúde, habitação, lazer, entre outros; e a partir daí, se verifica diferentes níveis de qualidade de vida na cidade de Mossoró (PINHEIRO, 2006).

O que nos impõe o entendimento de que a cidade não é a simples materialização de um conjunto de usos do solo justapostos. Da mesma maneira, a compreensão da cidade como uma justaposição de localidades não responde à maioria das questões que colocamos. Para isso, devemos compreender a cidade como uma articulação entre localizações, sem nos esquecermos que novas localizações alteram a estrutura do restante da cidade. No nível da rede urbana, há articulação entre as situações urbanas e a combinação das localizações e situações que implicam em transformações nos fluxos e fixos de pessoas e de mercadorias (WHITHACKER, 2007, p. 3).

Assim, os espaços vão sendo produzidos pela dinâmica econômica do lugar e os efeitos produzidos pela articulação da mesma com a formação de um conjunto de inovações. Tais, se delineiam não apenas pela força de trabalho,mas pela produção espacial, com a introdução de investidores e de alargamento do perímetro urbanizado. De acordo com Rocha (2005), o processo de valorização de zonas desocupadas, pelo 
capital imobiliário, obedece a diferentes mecanismos. Um deles é a urbanização de áreas mais distantes, sendo posteriormente valorizadas e presumidamente utilizadas para fins comerciais, configurando-se assim como uma dinâmica especulativa da cidade.

O espaço urbano torna-se então o espaço definido por uma certa, parte da força de trabalho delimitada, ao mesmo tempo, por um mercado de emprego e para uma unidade (relativa) de seu cotidiano.Podemos pensar, por exemplo, na dificuldade de estabelecer a unidade de uma região urbana como elemento produtivo (pois os fluxos econômicos formam um encadeamento contínuo), ainda que o mapa das migrações alternantes sirva, geralmente, para delimitar uma área urbana.O "urbano", enquanto conotação do processo de reprodução da força de trabalho, e o "espaço urbano", como o que auxilia a exprimir unidades articuladas deste processo são noções que nos permitem, assim o acreditamos, abordar teoricamente as questões que acabamos de colocar (CASTELLS, 2006, p. 336)

Contudo, a premissa teórica nos remete a pensar que a expansão urbana de Mossoró foi deflagrada por um conjunto de circunstâncias e dentre elas a questão econômica merece seu valor. A infra-estrutura urbana foi sendo construída e melhorada à medida que, os espaços foram sendo demandados e utilizados frente às transformações e inovações do processo de crescimento econômico e social da cidade.

\subsection{0 caso da Avenida João da Escóssia}

A Avenida João da Escóssia consiste atualmente em um dos locais de destaque nessa fase de metamorfose urbana em Mossoró/RN. A referida Avenida situa-se num eixo considerado área nobre da cidade, sua extensão atravessa os seguintes bairros: Centro, Doze Anos e Nova Betânia. A presença de empreendimentos como um Shopping Center (Mossoró West Shopping) e uma Universidade Privada (UnPUniversidade Potiguar), tem influenciado na dinâmica local. Tal eixo de transformação é hoje para Mossoró uma referência. Pois, a valorização e a especulação imobiliária do local tem contribuído na formação de uma nova centralidade. Parafraseando Arantes 
(2009, p. 14), o que, aliás, não deveria surpreender, pois o seu cenário de origem vem a ser o do movimento de volta à cidade, no mais das vezes dando origem aos conhecidos processos de gentrification (ou "revitalização urbana", conforme preferem falar seus promotores), em grande parte desencadeados pelo reencontro glamoroso entre Cultura (urbana ou não) e Capital.

Visto que, as dinâmicas introduzidas nesse local, são frutos da extensão da Avenida permeada pela construção, a priori do Shopping. É válido ressaltar, que anterior à chegada desse empreendimento, nessa área, o que existia era um conjunto de lotes (terras de propriedade privada), com baixo valor para à aquisição. Contudo, a presença de investimento pela iniciativa privada, com a construção do Shopping, motivou a expansão da via de acesso ao mesmo, estendendo-se atualmente numa área ainda maior.Pois ,a presença do mesmo articulou fluxos e desempenhou um papel fundamental para o estabelecimento de um outro empreendimento de grande valor nesse espaço:A Unp (Universidade Potiguar).

As elites abandonaram o centro, deslocando-se para áreas de serviço e comércio mais definidos e especializados, mas, nem por isso, ele está abandonado.Esse processo foi, aliás, criticamente estudado por Flávio Villaça (2001), mostrando como as elites brasileiras utilizam as estratégias de qualificação, requalificação e obsolescência constante dos espaços das cidades, desde as franjas marítimas aos pitorescos lugares históricos (FERREIRA e MARQUES, 2000, p. 03).

A Unp, permitiu ao local uma perspectiva diferenciada e juntamente com o Mossoró West Shopping uma valorização econômica do espaço, através da expansão da via e da chegada de outros empreendimentos. Dessa forma, a especulação imobiliária acontece com a construção de condomínios fechados nesse local e nas glebas, antes vazias, hoje tornou-se espaço de disputa e de valorização pelo enobrecimento da área. Assim, o impacto social e econômico desse local para Mossoró é perceptível norteando nesse contexto, a formação de uma centralidade alicerçada nos fluxos das dinâmicas sócio-espaciais existentes por parte dos agentes desse processo. 
Com isso,

\begin{abstract}
Essa centralidade também não se define apenas no nível intra-urbano, mas na articulação de diferentes níveis e escalas, sobretudo quando se restringe a elaboração do modelo teórico à concepção de hierarquia urbana tradicional, mas sim compreende a constituição de redes num padrão não necessariamente concêntrico e que possui articulações definidas por fluxos. Portanto, não apenas a definição da centralidade no tecido urbano se dá pelos fluxos e é dinâmica, mas também a centralidade pensada em escala da rede, ambas podendo, conforme características e tempos sobreporem-se (WHITACKER, 2007, p. 3).
\end{abstract}

Daí a justificativa para o alto valor dos condomínios residenciais do local. O caráter seletivo, se mostra pelo atendimento das necessidades e do enobrecimento da área por parte de empreendimentos de grande porte, além do alto valor de representação econômica e social para a cidade, sobretudo. Com isso, as metamorfoses do espaço construído manifestam a articulação, não só com a cidade, mas com a circunvizinhança que visita o local e que investe. Todavia, os agentes dessa transformação possuem um perfil associado aos condicionantes que motivam o investimento no local, contribuindo desse modo, para atrair novos investidores e agentes formadores dessa centralidade. Mas,

Embora se saiba que as cidades modernas sempre estiveram associadas à divisão social do trabalho e á acumulação capitalista, que a exploração da propriedade do solo não seja um fato novo, e que haja - como mostrou à exaustão Lefèbvre e depois toda a geografia humana recente- uma relação direta entre a configuração espacial urbana e a produção reprodução do capital, como estamos vendo, há algo de novo a registrar nessa fase do capitalismo em que as cidades passaram elas mesmas a serem geridas e consumidas como mercadorias (ARANTES, 2009, p. 26).

Fato este que pode ser percebido na referida Avenida, em que o solo passou a ser valorizado em função de empreendimentos de grande porte instalados no lugar, enquanto a perspectiva de comercialização cresce a medida que tais investimentos possibilitam uma aproximação ainda maior da classe média no local.Contudo a 
valorização do lugar também pode ser atribuída a um conjunto de dinâmicas produzidas pelo alto fluxo de pessoas diariamente, já que particularmente na Universidade Privada situada na mesma , circulam em média 5000(cinco mil alunos), o Shopping atende a esta demanda e sobretudo é referência na região atraindo pessoas de vários municípios que se localizam até $100 \mathrm{Km}$ (cem quilômetros da cidade), além de um supermercado de grande porte com vendas a varejo e atacado possibilitando nessa perspectiva uma descentralização das atividades comerciais em relação ao centro da cidade.

É útil considerar o sentido dessa mudança por uma variedade de razões. Para começar, o ambiente construído constitui um elemento de um complexo de experiência urbana que há muito é um cadinho vital para se forjarem novas sensibilidades culturais. A aparência de uma cidade e o modo como os seus espaços se organizam formam uma base material a partir da qual é possível pensar, avaliar e realizar uma gama de possíveis sensações e práticas sociais (HARVEY, 2007, p. 69).

Desse modo, as pressões competitivas norteadas pela lógica globalizante da economia influenciam este eixo de crescimento na cidade, pois a mobilização presente no processo determina as configurações existente no lugar, trazendo á tona uma rotina, que muda o perfil e o comportamento, além dos valores e da tradição.Todavia, o alicerce dessa mudança pode ser compreendido á luz de uma nova concepção de produção e de consumo, calcada na perspectiva modernizante dos padrões de morar e também de consumir.

Todavia,

Aí o embrião de uma mudança emblemática; à medida que a cultura passava a ser o principal negócio das cidades em vias de gentrificação, ficava cada vez mais evidente para os agentes envolvidos na operação que era ela, a cultura, um dos mais poderosos meios de controle urbano no atual momento de reestruturação da dominação mundial (ARANTES, 2009, p. 33).

É nesse contexto, que a identidade vai sendo produzida e a cultura vai proporcionando tais mudanças. Já que, pode se tomar como base a freqüência ao Shopping um elemento constitutivo dessa mudança, em que há uma preferência e um 
público, o qual é selecionado mediante as vias de acesso e do poder aquisitivo de adquirir mercadorias. Assim, como serve de analogia o quantitativo de alunos que freqüentam a Universidade Privada, tendo em vista que apesar dos incentivos no país de acesso ao ensino superior, os mesmos ainda não são suficientes para que esse acesso represente democraticamente o uso desse espaço.

A curto prazo, uma transição de mecanismos planejados para mecanismos de mercado pode combinar temporariamente usos distintos em interessantes configurações, mas a velocidade da gentrificação e a monotonia do resultado sugerem que, em muitos casos, o curto prazo é na verdade bem curto.A alocação de mercado e de terra de aluguel dessa espécie já enquadrou muitas paisagens urbanas em novos padrões de conformidade.O populismo do livre mercado, por exemplo, encerra as classes médias nos espaços fechados e protegidos dos shoppings e átrios, mas nada faz pelos pobres, exceto ejetá-los para uma nova e bem tenebrosa paisagem pós-moderna de falta de habitação (HARVEY, 2007, p. 79).

Com isso, percebe-se que a construção de um lugar voltado para atender as demandas das classes sociais, médias e alta, vem provocando nessa perspectiva um crescimento da cidade, mas que, sobretudo segrega e exclui. Com isso, os padrões dominantes de desenvolvimento das cidades nos dias atuais ainda seguem a uma lógica perversa de um capitalismo moldado pelas nuances da classe que demanda 0 processo acumulando lucros, a partir de um cenário formatado pelos agentes desses processos transformadores.

Nesse ínterim, vale ressaltar, que no espaço analisado os desafios que compõe a intervenção aliam-se a um conjunto de fatores deliberados pela necessidade de um planejamento sustentável, á medida que, a impermeabilização do solo a partir de um conjunto de construções no local, sem uma perspectiva sustentável podem provocar um comprometimento na qualidade de vida das pessoas de um modo geral, além de influenciar diretamente nos padrões climáticos da região. Posto que, numa região semiárida há uma tendência para o aumento da temperatura, fator este atribuído sobretudo pela baixa taxa de pluviosidade da região. 
O documento do Ministério do Meio Ambiente - MMA intitulado "Cidades Sustentáveis" (2003) estabelece quatro princípios com base na sustentabilidade, necessários para o desenvolvimento sustentável das cidades brasileiras:

1. Aperfeiçoar a regulação do uso e da ocupação do solo urbano e promover o ordenamento do território, contribuindo para melhoria das condições de vida da população, considerando a promoção da eqüidade, eficiência e qualidade ambiental.

2. Promover o desenvolvimento institucional e o fortalecimento da capacidade de planejamento e gestão democrática da cidade, incorporando no processo a dimensão ambiental urbana e assegurando a efetivação, participação da sociedade.

3. Promover mudanças nos padrões de produção e consumo da cidade reduzindo custos e desperdícios e fomentando o desenvolvimento de tecnologias urbanas sustentáveis.

4. Desenvolver e estimular a aplicação de instrumentos econômicos no gerenciamento dos recursos naturais visando a sustentabilidade urbana.

Apesar, desses princípios há um aspecto essencialmente intrínseco ao plano diretor que é a ordenação do uso e ocupação do solo urbano, processo mais conhecido como zoneamento urbano.

A gestão territorial, das cidades brasileiras pressupõe a implementação de uma política de engajamento da comunidade municipal e dos Poderes Legislativo e Executivo dos Municípios. Voltada para a promoção humana e da cidadania, para o desenvolvimento urbano, para o aperfeiçoamento das instituições e para o controle social das decisões de planejamento urbano, a gestão do território é antes de tudo política. É pressuposto da gestão territorial a participação dos cidadãos e deve levar em conta a organização do Estado Democrático de Direito.

Por isso, a política ambiental deve estabelecer um senso geral de orientação para as organizações e simultaneamente fixar os princípios de ação pertinentes aos assuntos e à postura empresarial relacionada ao meio ambiente.

Assim, é importante considerar o avanço e o crescimento das cidades, como fator propulsor da economia, mas é nítido também entender a contrapartida desse processo sem um planejamento adequado, que priorize além do desenvolvimento 
urbano dos espaços e dos fluxos construídos, uma política de sustentabilidade e de governança nas cidades.

\section{3 À guiza de conclusão}

O trabalho permite concluir que as atuais intervenções nas cidades, fazem parte a priori, de uma perspectiva estratégica de crescimento das cidades. Contudo, há uma necessidade de um planejamento nesses espaços que aliem desenvolvimento econômico a minimização da segregação dos mesmos.

Já que,

O espaço é um produto material em relação com outros elementos materiais, entre outros, os homens, que entram também em relações sociais determinadas, que dão ao espaço (bem como aos outros elementos da combinação) uma forma, uma função, uma significação social. Portanto, ele não é uma pura ocasião de desdobramento da estrutura social, mas a expressão concreta de cada conjunto histórico, no qual uma sociedade se especifica (CASTELLS, 2006, p.182).

Pois, foi entendido no caso exposto que a expansão da Avenida e a construção de grandes empreendimentos proporcionou a ampliação de um novo eixo de crescimento da cidade. Porém, agregou a este fato um conjunto de circunstâncias que incluem a mudança nos estilos de vida, a introdução de novos costumes e a segregação do espaço, motivada, sobretudo pelo padrão aquisitivo de consumo e de acesso aos lugares construídos como o Shopping e a Universidade Privada.

Assim, é possível compreender a lógica capitalista que direciona a meta desse eixo de crescimento, haja vista, os agentes do processo em sua grande parte aparecem como investidores privados, mas que, tiveram incentivo por parte do poder público para se instalarem no local. 
Desse modo, a valorização das glebas vazias e a introdução da presença de condomínios de luxo na área justificam a assertativa e levam a uma inquietação acerca da sustentabilidade do lugar, no que se refere aos padrões de produção e consumo atualmente discutidos e ora propostos pela Política de Desenvolvimento das Cidades.

Com isso, é necessário mostrar que há um lado positivo no processo estudado, quando impulsiona a economia e promove um fluxo maior na cidade de pessoas. Mas, também é possível perceber que o lado negativo da situação está na segregação do espaço e na mudança nos estilos de vida, além da valorização das glebas vazias impulsionarem à uma especulação imobiliária forjando nesse contexto, um cenário excluidor e segregador, que afasta a população do lugar, em parte pelo uso e outra pela ocupação de espaços novos e/ou renovados na cidade de Mossoró.

\section{REFERÊNCIAS}

ARANTES, O. Urbanismo em fim de linha. São Paulo: Edusp, 1998.

FELIPE, J.L.A. A (re) invenção do lugar: os Rosados e o "país de Mossoró". João Pessoa: Grafset, 2001.

A organização do espaço urbano de Mossoró. Coleção Mossoroense, série C. Mossoró: Fundação Guimarães Duque, 1982.

BOTELHO, T.R. Revitalização de centros urbanos no Brasil: uma análise comparativa das experiências de vitória, Fortaleza e São Luiz. Disponível em <www.scielo cl/pdf/eure/v31n93/art04.pdf> acesso em 20 jan 2007.

CAMPOS, H.A. Refletindo sobre o papel das representações nas territorialidades urbanas: o exemplo da área central do Recife. IN: GEOUSP - Espaço e Tempo, São Paulo, no 11 p 35-50, 2002. Disponível em <www.geografiafflch,usp.br/publicacoes> acesso em 10 jan 2007.

CASTELLS, M. A questão urbana. 3 ed.São Paulo: Paz e Terra, 2006.

CYMBALISTA, R. A trajetória recente do planejamento territorial no Brasil In: Revista

Paranaense de Desenvolvimento, Curitiba, n.111,2006. 
DUARTE, R.G. O processo de reabilitação e renovação urbana na cidade do Rio de Janeiro e suas perspectivas. In: Revista Electrónica de Geografia 4 Ciencias Sociales - Scripta Nova.Disponível em <www.ub.es/geocrit/sn/sn-194-44> acesso em 10 fev 2007.

FRUGOLI, JR.H. Centralidade em São Paulo: trajetórias, conflitos e negociações na metrópole.São Paulo: Cortez/EDUSP, 2000

FERREIRA, A.L.A; MARQUES, S. Privado e Público: Inovação Espacial ou Social? In. Revista Electrónica de geografia y ciências sociales: Scripta Nova. ISSN 1138-9788. Disponível em www.ub.es/geoeritisn 69-20 acesso em 10 jan 2007.

SOUZA, F.F. de. História de Mossoró. 3 ed. Coleção Mossoroense. Mossoró: ESAM, 2001.

HALL, P. Cidades do amanhã. São Paulo: Perspectiva, 2005.

HARVEY, D. Espaços de Esperança. São Paulo: Loyola, 2004.

Condição Pós- moderna. São Paulo: Loyola, 2007.

IDEMA - Instituto de Desenvolvimento Econômico e Meio Ambiente. In: Perfil do seu município - Mossoró. Disponível em <www.idema.rn.gov.br>. Acesso em27/11/2009.

JACOBS, J. Morte e Vida de grandes cidades. São Paulo: Martins Fontes, 2000.

LEITE, R.P. contra. Usos e espaço público: notas sobre a construção social dos lugares na Manguetown. Ver. Brás. Soc. São Paulo, v. 17, n 49, 2002. Disponível em < http://www.scielo.br> acesso em 10 de fev. 2007.

NOBRE, E.A.C. Intervenções urbanas em Salvador: Turismo e "gentrificação" no processo de renovação urbana do Pelourinho. In: X Encontro Nacional da Anpur. Disponível em <www.usp.br/fau/docentes/depprojeto/e_nobre/intervencoes-urbanassalvador> acesso 10 já. 2007.

RANCIÈRE, J. O desentendimento. São Paulo: Editora 34, 1996.

RIBEIRO, L.C.Q.; PECHMAN, R.(org). Cidade, povo e nação: gênese do urbanismo. Rio de Janeiro: civilização brasileira, 1996.

RIBEIRO, L.C.Q. (org.). Metrópoles: entre a coesão e a fragmentação, a cooperação e o conflito. São Paulo: Abramo, 2004.

ROCHA, A.P.B. Expansão urbana de Mossoró: período de 2000 a 2004. Natal/RN: Edufrn, 2005. 
SANTOS, M. O espaço dividido. 2 ed.São Paulo: Editora da USP, 2008.

SERPA, A. O espaço público na cidade contemporânea. São Paulo: Contexto, 2007.

SILVA, R.N. da. Evolução Urbanística de Mossoró. 2ed. Coleção Mossoroense. Mossoró: ESAM, 1983

SILVEIRA, J.A.R.; RIBEIRO E. Novas centralidades e expansão intra-urbana. Disponível em< vivercidades.com $>$ teses.UFPB.2008.

SMITH, N. The new urban frontier: gentrification and reveanchist city. Londres: Routledge,1996.

SOUZA, M.L. Mudar a cidade. 5 ed.Rio de Janeiro: Bertrand Brasil, 2008.

SPOSITO (org).Cidades Médias: produção do espaço urbano e regional.1ed. São Paulo: Expressão Popular, 2006.

SPOSITO, M.E.B. Capitalismo e urbanização. 8 ed. São Paulo: Contexto,1997.

TEIXEIRA. J.S.; OLIVEIRA. M.A. (org). Neoliberalismo e reestruturação produtiva. 2ed. São Paulo: Cortez, 1998.

VILLAÇA, F. Espaço intra-urbano no Brasil. São Paulo: FAFES P/ Studio Nobel, 2001.

WHITACKER, A. M.I novações Tecnológicas, mudanças nos padrões locacionais e na configuração da centralidade em cidades médias.In:Revista eletrônica de Geografia y ciências sociales: Scripta Nova.Vol.XI №.245. ANO 2007.ISSN:1138-9788.

ZACHARIASSEN, C.B. De volta à cidade, dos processos de gentrificação às políticas de "revitalização" dos centros urbanos. São Paulo: Annablume, 2006.

ZANCHETTI, S.M. Novas estratégicas de conservação e gestão urbana. Disponível em www.urbanconservation.org/textos/scarlos.htm acesso em 16 jan. 2007.

ZUKIN, S. "Paisagens urbanas pós-modernas: mapeando cultura e poder" In: ARANTES, A. (org). O espaço da diferença. São Paulo: Papirus, 1999. 